\title{
PEDAGOGIA UNIVERSITÁRIA: GÊNESE FILOSÓFICO-EDUCACIONAL E REALIZAÇÕES BRASILEIRAS NO SÉCULO XX
}

\author{
UNIVERSITY PEDAGOGY: EDUCATIONAL-PHILOSOPHICAL ORIGIN \\ AND BRAZILIAN CORRELATED ASPECTS AT THE $20^{\mathrm{TH}}$ CENTURY \\ PÉDAGOGIE UNIVERSITAIRE : GENÈSE PHILOSOPHIQUE- \\ ÉDUCATIONNELLE ET RÉALISATIONS BRÉSILIENNES AU XXE SIĖCLE \\ PEDAGOGÍA UNIVERSITARIA: GÉNESIS FILOSÓFICO EDUCACIONAL \\ Y REALIZACIONES BRASILENÃS EN EL SIGLO XX
}

José Carlos Souza Araújo *

\section{RESUMO}

O objetivo deste é configurar uma conceituação de pedagogia universitária, primeiramente com base no pensamento de Wilhelm von Humboldt (1767-1835), presente na obra intitulada Sobre a Organização Interna e Externa das Instituiçôes Científicas Superiores em Berlim, escrita em 1810, a qual revela, basicamente, o ideário em torno de universidade desde o século XIX aos nossos dias. E, em segundo lugar, complementarmente, o objetivo de versar sobre a pedagogia universitária brasileira, certamente vinculada aos ideais humboldtianos, em três momentos cruciais de sua constituição no decorrer do século XX: a) nos anos 1920, pelo movimento universitário fundado na idéia de formação das elites; b) nos anos 1950 e 1960, pelo movimento em torno da democratização da Educação Superior; e c) nos anos 1990, com ressonâncias na atualidade, pelo movimento denominado 'mercantilização' da Educação Superior, quando se assiste a uma admirável expansão do setor privado, mas certamente em sintonia com o movimento anterior.

Palavras-chave: Pedagogia universitária. Humboldt. Universidade. Ensino e pesquisa. Universidade brasileira. Educação superior.

* Doutor em Educação pela Universidade Estadual de Campinas (1995). Professor Permanente do Programa de Pós-Graduação em Educação do Centro Universitário do Triângulo, Uberlândia, MG. Professor Colaborador da Universidade Federal de Uberlândia, MG (jcaraujo@ufu.br). 
Para efeito de definição de objeto, tomar-se-á a orientação iluminista que se expressa desde Kant (1724-1804), particularmente em sua obra O Conflito das Faculdades (1993), e por aqueles que estiveram envolvidos, pela Ilustração, com a constituição da universidade alemã, concretamente a partir das primeiras décadas do século XIX: entre eles, pela ordem, Herder (1744-1803), Fichte (1762-1814), Humboldt (17671835), Schleiermacher (1768-1834), Schelling (1775-1854).

É no interior da Ilustração que o termo formação - em alemão bildung - se explicita como relevante em termos educacionais. E a emergência da pedagogia universitária, de expressão iluminista, está intrinsecamente vinculada a tal categoria, também de longa duração. Bibliograficamente, na "[...] segunda metade do século XVIII aparecem na Alemanha mais escritos e artigos sobre educação e ensino que nos três séculos anteriores" (GINZO, 1991, p. 8) - é o que registra esse autor ao comparar as expressões entre os humanismos renascentista e alemão, conhecido este também por neo-humanismo.

Em relação à constituição dos graus de ensino: no caso da Educação Superior, é no andamento do século XIX que a universidade moderna, instaurada sob a inspiração iluminista, tem uma significativa expansão, bem como uma dupla e concreta orientação, sob tensão, entre a formação acadêmica e a formação profissional. Evidentemente, as origens da universidade encontram-se ao final do século XI quando, desde então, vieram se firmando no ocidente as Faculdades Superiores - Teologia, Medicina e Direito - e a Inferior, a de Artes, tradição esta presente até os finais do século XVIII. Desde então, quebra-se a estrutura organizacional fundada em tais Faculdades (RIDDERSYMOENS, 1994).

É também no andamento do século XIX que a escolarização primária se efetiva, bem como a disseminação dos jardins da infância, criados em 1837 por Froebel (1782-1852). Além disso, o século XIX é também o século da explicitação dos sistemas nacionais de ensino, pelo menos entre os países hegemônicos de então, sem dúvida, uma expressão da constituição dos Estados-Nação. Com relação ao ensino secundário, sua gênese está associada aos séculos XV e XVI.

Por isso, abordar o que é pedagogia universitária implica investigar sobre a gênese da universidade iluminista, concretamente realizada a partir do alvorecer do século XIX, particularmente em Wilhelm von Humboldt (1767-1835), entre outros, porque inaugura ele na Universidade de Berlim tal projeto. Iluminista porque é sob esse ideário, manifesto desde os meados do século XVIII, que a consolidada universidade medieval se refaz em busca de identidade em vista dos novos tempos, agora urbanos, industriais e tecnológicos. As revoluções comercial e industrial promoveram um novo entendimento filosófico-político assentado no liberalismo, associado ao jusnaturalismo e ao contratualismo. Se o iluminismo, desde os meados do século XVIII, representa para a Modernidade o mergulho mais significativo em busca do novo, do atual, em oposição ao tradicional, ao antigo e ao antiquado, a mesma Modernidade somente triunfa no campo 
da Educação Superior meio século depois. Entretanto, não significa que a universidade medieval tenha vivido sem turbulências desde as mesmas origens da Modernidade no século XIII (LIMA VAZ, 1991).

Cabe ainda esclarecer a respeito da etimologia das palavras que compõem a locução pedagogia universitária. Tais termos, como locução, equivalem a um só vocábulo, e apresentam um significado que se identifica pela conjugação de duas palavras dignas de apreço no âmbito do processo de escolarização da cultura ocidental, conforme se comentou há pouco a respeito dos graus de ensino e de suas explicitaçóes históricas.

Assim sendo, para compreender porque tal locução passa a ganhar, semanticamente, uma função única, convém compreender que a universidade era, em seus primórdios, apenas uma corporação. "Estava constituida exclusivamente por um grupo de pessoas sem nenhum haver comum. [...] quando a Universidade entrava em conflito com as autoridades eclesiástica e civil, [...] suspendia as aulas, mudava-se para outro local ou dispersava-se" (DURKHEIM, 1995, p. 90). Segundo esse mesmo autor, o termo universidade é sinônimo de societas, de consortium, ou seja, tem o sentido de corporação, o qual é também usado para designar corporaçōes industriais ou mesmo outras corporações que detivessem uma relativa unidade moral.

Em suma, através do próprio Durkheim, tem-se a significação do que era uma universidade:

[...] esse termo não tinha em si e em grau nenhum significado escolar e pedagógico. Durante muito tempo, quando se quisesse dar-lhe esse sentido especial, era preciso determiná-lo através de outras expressōes. Dizia-se Universitas magistrorum et scolarum, ou ainda Universitas studii. A palavra Studium era, com efeito, a mais utilizada para indicar a vida pedagógica que se desenvolvia dentro da corporação (1995, p. 91).

E pedagogia significa, etimologicamente, a ação de conduzir a criança, em conformidade com a herança da cultura grega; entretanto, na cultura romana do segundo século de nossa era, já há referência muito semelhante à significação atual. Para além de sua etimologia, esta assume variações que vão desde o processo de condução da educação - muitas vezes enfaticamente concebido como eminentemente prático e, por vezes, negando-se a dimensão teórica; mas, certamente passando pela abordagem de que ela seja uma área de conhecimento, que se estrutura em torno de princípios e diretrizes, os quais têm em vista a ação de educar. Assim sendo, a compreensão do que é pedagogia tem oscilado, pelo menos comumente, entre ser prático sem ser teórico, ou ser teórico para ser prático, ou ser teórico-prático ou vice-versa. Parece ser essa associação entre a prática e a teoria uma dimensão fundamental para se compreender o que é pedagogia.

Dessa forma, pode-se falar em pedagogia universitária desde o tempo medieval, quando se deu a gênese da universidade, segundo aqueles moldes há pouco apontados pelas observaçôes de Durkheim; entretanto, não se pode afirmar que a pedagogia universitária 
seja uma só em termos de princípios e diretrizes, ou mesmo que tenha tido uma estrutura organizativa em um estabelecimento definido, que sustentasse o seu desenvolvimento. Pelo contrário, são muitas as pedagogias universitárias, se se levam em conta os nove séculos que viram a universidade, particularmente desde o âmbito da cultura ocidental, fazer-se, consolidar-se e refazer-se. Sua história, em diferentes países, expressa essa dinâmica que se revela pela apropriação, veiculação e disseminação de concepções e de realizações diversas.

Retomando a orientação de Durkheim: não havia uma universalidade do saber. "[...] a Universidade começou sendo um agrupamento de individuos e não um agrupamento de ensinos. Expressou, inicialmente, a solidariedade dos mestres muito antes do que a solidariedade do ensino; [...]" (1995, p. 92). Em atenção ainda à dimensão que funda a pedagogia universitária desde então, pode-se afirmar: " $O$ fato primitivo é mesmo o agrupamento das pessoas, o agrupamento dos mestres; ele é que sugeriu a idéia de agrupar os estudos, os ensinos e concentrá-los" (DURKHEIM, 1995, p. 92).

Por conseguinte, pode-se compreender que pedagogia universitária seja uma locução que se estabelece como relação em vista das conexōes entre a universidade e a sociedade. A Universidade medieval não surgiu preocupada em concentrar enciclopedicamente todas as áreas. Nem mesmo cada uma das primitivas universidades possuía todos os cursos de então - os de Teologia, Direito, Medicina e Artes. É necessário compreender que as expressóes universitárias sejam diversas em sociedades diferenciadas, desde o campo europeu medieval. E tal conexão entre universidade e sociedade implica uma pulsação que guarda relações contextuais, dos pontos de vista geográfico, cultural, institucional, político, econômico, entre outros aspectos.

Em síntese, a pedagogia universitária estrutura-se em torno de princípios, diretrizes e ações dedicados à educação do jovem, o que implica, em sua imediatez, a construção da vida adulta. Embora a escolarização ocupe a infância, a adolescência e a juventude, é a essa última que está ligada a pedagogia universitária, e é através dessa fase que ela se realiza, pelo menos em linhas gerais e, quando não, há uma aspiração politicamente constituída para que ocorra entre os 18 e 24 anos, como acontece em nossa época. Entretanto, a pedagogia universitária não guarda relação apenas com essa etapa da vida: se se leva em conta a necessária pulsação entre a universidade e a sociedade, é a tal pulsação que cabe responder a pedagogia em apreço. Nesse sentido, a pedagogia universitária não tem idade, porque sua foz desemboca no oceano social. A educação superior brasileira, contemporaneamente, é disso uma expressão concreta.

Nessa direção, muitas são as concepções de pedagogia universitária, uma vez que se considere a institucionalização da universidade iluminista em diferentes países nos últimos dois séculos. E esta seria uma abordagem histórica, a de indagar sobre as relações entre o professor e o aluno, mediadas pela pesquisa, pelo estudo, pelo ensino, pelas associações estudantis, pelos conselhos universitários de vária ordem; em suma, pela 
constante renovação da universidade destes últimos dois séculos em torno da formação acadêmica e da formação profissional, um binômio presente na vida universitária desde então, fazendo-a oscilar entre uma e outra, ou a enfatizar mais uma do que outra, ou mesmo assumindo-as como faces de uma mesma moeda.

Ainda a título introdutório, cabem algumas observaçōes sobre a relação entre pedagogia universitária e didática, ou talvez entre a pedagogia e a didática. Se a primeira se explicita pela ação de conduzir, mas não isenta ou desligada da teoria, a didática se realiza, também teórica e praticamente, pela explicitação do ensino. Didática deriva do verbo grego, dídaskó , e significa ensinar, instruir. Nesse sentido, os conceitos de educação, de pedagogia e de didática estão umbilicalmente interligados.

Faz-se mister reconhecer que as formas de ensino, âmbito da didática, constituem hoje um patrimônio que tem origens milenares. No entanto, é necessário situar que, do ponto de vista sistemático, a emergência da Didática tem sua gênese em Comênio (1592-1670), através de seu clássico, Didática Magna. E a pedagogia universitária, nesse particular, deve ser situada nesse processo teórico-prático, histórica e concretamente instituído pelos objetivos, pelos métodos e técnicas de ensino, pelas tecnologias educativas e pela avaliação da aprendizagem. A educação se realiza pela pedagogia, a qual a promove e a operacionaliza; e a didática, uma teoria-prática do ensino, efetiva-se pela orientação da pedagogia, que objetiva, em ultima instância, educar.

\section{A FUNDAÇÃO DA PEDAGOGIA UNIVERSITÁRIA ILUMINISTA}

A orientação que se pretende, nesta reflexão, é ressaltar a posição filosóficoeducacional em torno da universidade iluminista do alemão Wilhelm von Humboldt (1767-1835). Sua obra, vinda a público somente em 1899, é significativa, entre outras de sua autoria: trata-se de Sobre a Organização Interna e Externa das Instituiçôes Cientificas Superiores em Berlim, escrita em 1810, um texto fundador sobre a Universidade de Berlim, Alemanha, da qual foi reitor, desligando-se da mesma em abril de 1810, depois de se envolver nesse projeto desde os finais de 1808 (ROCHA, 1997).

Em Humboldt, encontra-se delineado, ainda que sucintamente, um projeto filosóficoeducacional, afeto às dimensões acadêmico-institucional, universitária, política, ética, educacional. E esse é o objeto desta reflexão.

Ao buscar explicitar o contexto intelectual prussiano em que nasce e se forma Humboldt, faz-se mister remeter-se à concepção iluminista que trouxe à luz ideais centrados na idéia de progresso, os quais estiveram intrinsecamente associados à educação (ARAUJO, 2007) - particularmente a escolar - como mediação para nortear e realizar o mesmo progresso. As discussões sobre tal temática, a do progresso associado à educação, presentes nas obras de Turgot, Kant, Condorcet, Voltaire, Herder, entre outros, no decorrer da segunda metade do século XVIII, explicitam tal norteamento. 
Tratava-se de iluminar, de trazer luzes à razão, enfim, de investir no esforço pelo esclarecimento de ordem intelectual: nesse diapasão, as ciências e a filosofia são convocadas a dar sustentação a esse projeto iluminista. Estava então em andamento a secularização da cultura, de uma maneira mais expressiva do que se punha desde os inícios da Modernidade no século XIII.

É nessa direção que várias obras, particularmente aquelas sobre universidade - desde os fins do século XVIII e primeiras décadas do século XIX - devem ser concebidas como expressões de um movimento de ordem intelectual, mas como exigências organizativoinstitucionais respondentes ao movimento da secularização da cultura. Exemplificando: é o caso de Kant, com a obra Conflito das Faculdades, de 1798; de Fichte, Por uma Universidade Orgânica: Plano Dedutivo para um Estabelecimento de Ensino Superior, de 1807; de Schleiermacher com Pensamentos de Circunstância sobre a Universidade segundo a Concepção Alemã, de 1808.

É no interior de tal contextualização de ordem intelectual e civilizatória, sob a direção iluminista, que se insere a obra de Humboldt, escrita em 1810, na verdade um texto sucinto e inacabado, mas lapidar enquanto manifestação teórico-filosófica sobre universidade; além disso, é um texto também preocupado com a organização e a gestão das instituições superiores. Nele está presente uma reflexão de quem trouxe à luz a Universidade de Berlim, e a geriu em sua implantação. Entretanto, para além do gestor que organizou tal implantação, a sua pequena obra expressa princípios que fundam uma concepção de pedagogia universitária que veio a conferir identidade à universidade iluminista, bem como inspirar o movimento universitário desde então.

Entre parêntesis: atente-se que as direções filosófico-educacionais assentadas no progresso e na educação, no iluminismo, na secularização, na visão de mundo liberal respondente aos novos tempos econômico, industrial, tecnológico, urbano - enfim, capitalistas -, qualificam a concepção de pedagogia universitária desde então aos nossos dias. Ressonâncias e desdobramentos estão presentes inclusive no atual movimento universitário brasileiro, assentado nas diretrizes da $\operatorname{LDB~n}^{\circ}$ 9.394, de 20 de dezembro de 1996, mas também pela Lei n ${ }^{\circ} 5.540$, de 28 de novembro de 1968. Tais aspectos serão melhor desenvolvidos na segunda parte desta reflexão.

O posicionamento inicial de Humboldt confere às instituições científicas superiores dois empreendimentos necessários à sua configuração: 1) desenvolvimento científico e 2) formação moral e intelectual. Segundo ele, "o conceito das instituições científicas superiores [...] implica duas tarefas. De um lado, promoção do desenvolvimento máximo de ciência. De outro, produção do conteúdo responsável pela formação intelectual e moral' (HUMBOLDT, 1997a, p. 79).

No entanto, essas duas tarefas não se põem como autônomas e complementares. $\mathrm{Na}$ verdade, revela Humboldt que as referidas instituiçôes internamente se organizam pela combinação da ciência objetiva com a formação subjetiva. Como se observa, as bases da 
concepção sobre o vínculo da pesquisa e do ensino nas instituições científicas superiores estão aí postas. Porém, esclarece Humboldt que o carro-chefe da mesma, bem como o seu objetivo, é a ciência.

E o desenvolvimento desta não pode obedecer a parâmetros externos à universidade. Em seu pensar, o desenvolvimento da ciência contém a sua própria finalidade, visto que a centralidade da instituição universitária está estabelecida na ciência, a qual, na verdade, deve-se constituir como diretora da "[...] produção do conteúdo responsável pela formação intelectual e moral (geistige und sittliche Bildung)" (HUMBOLDT, 1997a, p. 79). Internamente a tal assertiva, o seu posicionamento ganha clareza: "[...] as instituiçôes cientificas apenas se justificam plenamente quando as açôes que as definem convergem para o enriquecimento da cultural moral da Nação" (HUMBOLDT, 1997a, p. 79).

A esta altura, alguma síntese torna-se possível e necessária em vista de uma compreensão mais ampliada de seu posicionamento: a universidade se configura em torno da ciência, devotada à veiculação de conteúdos destinados à formação intelectual e moral, mas em última instância assentada num projeto de enriquecimento da cultura moral da Nação. Ou seja: estão aqui estabelecidos, sucintamente, os norteamentos filosóficos afetos à perspectiva científica, formativa, ética e nacional - esta, uma orientação filosófico-política - que guarda em seu interior uma concepção de Estado.

Este último aspecto remete às discussões sobre a concepção de educação nacional, ou seja, de educação como mediação para a construção da Nação. Embora elas já se expressem em textos de Erasmo de Roterdão e de Lutero no início do século XVI, as discussões afloraram com mais densidade no período de efervescência do Iluminismo, sobretudo no decorrer da segunda metade do século XVIII.

Conceber a educação como estruturante da nacionalidade é algo que está presente em escritos de Rousseau, La Chalotais, Diderot, Lepelletier, Fichte, entre outros. Estava aí em gestação a emergência do Estado Moderno que se afigura como representante da Nação. Conceber a universidade - uma forma específica de Educação Superior - como uma instituição devotada ao enriquecimento da cultura moral da Nação é revelar as marcas de uma discussão, que tem sua contextualização datada. O pensamento de Fichte, expresso na obra Discursos à Nação Alemã, de 1807-1808, manifesta a mesma preocupação, a de cimentar a vida nacional pela educação. Ou seja, uma comunhão de posiçóes em que a educação se constituía em norteamento mesmo da Nação e de seu povo: a locução educação nacional ganha aí uma semantização ímpar no seio da vida contemporânea. Entre parêntesis, o Brasil só veio a conhecer tal explicitação nos finais do século XIX: exemplar é a obra de José Veríssimo (1985), A educação nacional, publicada em 1890. Entretanto, segundo Lourenço Filho (1984, p. 371), essa locução só aparece pela primeira vez no Brasil em 1878.

Além disso, há uma outra dimensão a ser ressaltada: a de que a ciência deve ser orientadora da produção de conteúdos. Portanto, estes ganham sentido desde que 
orientados pela pesquisa e pelo desenvolvimento científico, e desde que se apresentem como intermediação em vista de um destino, que passa pela formação intelectual e moral, a qual por sua vez visa, em última instância, a cultura moral da Nação.

Em termos ético-acadêmicos, o posicionamento humboldtiano é também lapidar, pois a ciência, em sua concepção, goza de centralidade quando afirma: "Uma vez que estas instituiçôes só cumprem sua finalidade ao realizarem a idéia pura de ciência, os princípios mais importantes de sua organização se encontram na autonomia e na liberdade" (grifos do autor) (HUMBOLDT, 1997a, p. 80).

Tais princípios, na verdade, estruturam-se como guias, e se somados à cooperação e à colaboração, como o faz Humboldt (1997a, p. 80), configuram-se como basilares em sua concepção de universidade. Se de um lado a autonomia científica está vinculada à liberdade de investigação, e ambas se influenciando mutuamente na construção das relações entre os pesquisadores, estes contribuem para a vida da instituição universitária, desde que estabeleçam interações em vista da cooperação - expressa por Humboldt em duas perspectivas: (a) uma concebida como complementação mútua entre os cientistas e (b) a outra como geradora de entusiasmo entre eles. Trata-se, como se observa, de gerar no interior na universidade uma energia que alicerce as relações acadêmicas em vista do desenvolvimento científico.

Estão aqui expressos os quatro princípios da ética acadêmica a orientar as instituições científicas superiores - a autonomia, a liberdade, a cooperação e a colaboração -, os quais fundam os princípios condutores, bem como lançam as diretrizes para se pensar os fundamentos da pedagogia universitária. Etimologicamente, pela autonomia, estão expressos para a vida universitária - da qual a pedagogia universitária é cordial - os direitos de se reger através de leis próprias; pela liberdade, a referência fundamental é a condição de pessoa livre; pela cooperação, trata-se de trabalhar ou de operar em conjunto com, ou seja, explicita-se a perspectiva associativa em torno da pesquisa e do ensino; e, finalmente, pela colaboração, embora guarde as mesmas raízes com relação à cooperação, ressalte-se aqui o trabalho feito em comum. Nessa direção, compreende-se que a pedagogia universitária seja social, e não individualizada.

Tais princípios devem ser compreendidos em relação ao esclarecimento do próprio Humboldt com relação à centralidade de que goza a ciência em seu pensamento: "[...] numa instituição cientifica superior, o relacionamento entre professores e alunos adquire uma feição completamente nova, pois, neste ambiente, ambos existem em função da ciência" (1997a, p. 81). Tal orientação acaba por revelar que o ensino, em âmbito universitário, não deve se organizar em torno do que propriamente significa o ensino em versão dicionarizada, ou seja, como transmissão de conhecimentos.

Se ensinar deriva de insignire, que significa distinguir ou assinalar, tal dimensão etimológica é ultrapassada pela perspectiva posta por Humboldt: a de que o ensino resulta da pesquisa, e não esta daquele. Situar a pesquisa como norteadora do ensino 
implica, como já se viu anteriormente, elevar-se a um patamar guiado pela autonomia, pela liberdade, pela cooperação e pela colaboração. Se o aluno de nível superior deve assentar-se nesse patamar, trata-se de elevá-lo fundado nesses princípios orientadores.

Portanto, o ensino, concebido como transmissão de conteúdos, é secundarizado, e a pesquisa se manifesta como princípio organizador das relações entre o professor e o aluno, ainda que este se manifeste fragilizado em relação à vitalidade científica do professor. Mas é o norteamento pela pesquisa que deve balizar tais relações. Como afirma Humboldt, as instituiçóes universitárias devem se caracterizar pela "[...] vida intelectual dos que se dedicam à ciência e à pesquisa" (1997a, p. 81).

Sua concepção, nesse aspecto, estabelece o Estado com a obrigação de manter a dinâmica em vista do desenvolvimento máximo de ciência, concebendo-o como possuidor de uma lógica própria e interna à atividade científica. No entanto, não é somente a pesquisa que tem a sua própria lógica interna, mas também o conteúdo de ensino, destinado à formação intelectual e moral. "Esse conteúdo não pode ser determinado segundo uma intenção que the seja externa. Pelo contrário, contém sua própria finalidade" (HUMBOLDT, 1997a, p. 79). Dessa forma, em sua concepção, o Estado deve se manter isento em relação ao desenvolvimento científico, e intervir o menos possível.

Trata-se, como se deduz de tal princípio orientador para a política educacional de caráter universitário, mas também como demarcador do ponto de vista filosóficopolítico, de colocar a ciência como processo que se expressa por uma busca infindável, que orienta a instituição universitária como lugar de desenvolvimento científico, fundado na liberdade, na autonomia, na cooperação e na colaboração. No entanto, os vínculos com o Estado estão postos em sua obra, uma vez que este:

[...] não pode exigir das instituiçôes cientificas superiores nada que se relacione imediata ou diretamente a si mesmo. Ao contrário, deve compreender que, ao alcançarem sua autêntica finalidade, estas também cumprem as finalidades do próprio Estado (HUMBOLDT, 1997a, p. 89).

Nesse aspecto, faz-se necessário compreender o que é a Bildung (formação), mencionada na primeira página de seu texto (Ibidem, p. 79): trata-se de uma categoria de longa duração, e de tradição alemã, que é, filosoficamente, basilar desde a segunda metade do século XVIII aos nossos dias. As perspectivas assentadas na autonomia e na maioridade sustentadas pela filosofia alemã estão, particularmente, presentes em Kant (1724-1804), por exemplo, através de Resposta à pergunta: Que é "Esclarecimento"? ('Aufklärung') (1974) e de Sobre a Pedagogia (1996).

Etimologicamente, são importantes as seguintes demarcações:

A palavra Bildung, em alemão, significa propriamente 'configuração'. Vem de Bild, que designa toda representação de coisas em uma superficie: são Bild um desenho, uma foto, um quadro, uma estampa. Passando deste sentido fisico ao figurado, Bild significa imagem, representação, figura, forma [...]. O termo grego plasma, e seu equivalente latino formatio, se traduz em alemão por 
Bildung, talvez desde Kant. O verbo bilden significa representar, formar, configurar. Na linguagem pedagógica, a Bildsamkeit (formabilidade) será a disposiçāo do indivíduo em adquirir alguma caracteristica: por exemplo, em J.F. Herbart [1776-1841] é a disposição à moralidade (CABANAS, 1995, p. 34).

Nessa direção, há muitas formas de se percorrer por esse oceano em que se constitui a pedagogia universitária. Epistemologicamente, pode-se assumir que tal locução se situa na fronteira de diversas áreas, cujos espaços limítrofes estão, particularmente, vinculados à área da Educação, que congrega a Filosofia, a Sociologia, a Política, a História, a Economia entre outras. Paradigmaticamente, a busca pela definição do significado de pedagogia universitária implica múltiplos saberes, desde o filosófico-educacional aos científico-educacionais, mas também aos saberes técnicos expressos pela constituição da própria pedagogia e da didática.

Retornando aos norteamentos de Humboldt: em uma outra obra, cujos fragmentos estão reunidos em Escritos de Filosofia de la História, mas elaborados em épocas diferentes, Humboldt situa a formação como uma força que impulsiona a história humana: " $A$ força da formação é o que se esforçam por alcançar as naçôes e os indivíduos. Nesse âmbito exercem seu poder as idéias, e aqui surge a importante questão de marcar os limites da formação em vista do para onde podem conduzir" (HUMBOLDT, 1997b, p. 45-46).

Para ele ainda, há "[...] certo ciclo de idéias gerais que, mais que comunicadas, estão presentes por si mesmas imediatamente e em qualquer parte nas forças de pensar e de sentir do ser humano" (HUMBOLDT, 1997b, p. 46). Tais idéias estão ancoradas na religião, na constituição política, na vida pública e doméstica, traduzindo-se nas diversões, na arte, na filosofia e na ciência; e são tais idéias as que constituem as forças formadoras das nações. Todavia, segundo o seu entendimento, tais forças podem ser dinamizadoras, bem como promotoras de inércia em relação à vida intelectual e moral das nações, desde que se deixem dominar pelos costumes e pelas paixões.

Tal concepção acaba situando a universidade como um local em que a ciência e a política se expressam coadjuvantes, aquela construtora deste. Não há uma dicotomização entre a instituição universitária e o Estado. Pelo contrário: "[...] a universidade mantém sempre uma relação intrínseca com a vida prática e com as necessidades do Estado, já que, ao orientar a juventude, desempenha tarefas pragmáticas que interessam ao Estado" (HUMBOLDT, 1997a, p. 94-95).

Em síntese, as balizas postas por Humboldt se explicitam em torno da pesquisa e do ensino, concebidos como indissociáveis, mas este sob a tutela daquela. Para isso, a autonomia, a liberdade, a cooperação e a colaboração são mediações que visam estruturar as condições para o desenvolvimento científico. O papel do Estado aí se configura como uma obrigação, a de propiciar as condições para o desenvolvimento científico, o qual, em última instância, ressoa em vista das finalidades do Estado, bem como de suas necessidades. Se a concepção de Nação em seu texto aparece dissociada das concepções 
que expressam o que é o Estado, significa que este é posto a serviço daquela. As realizações do Estado têm em vista o enriquecimento da cultura moral da Nação.

\section{A PEDAGOGIA UNIVERSITÁRIA BRASILEIRA E SEU MOVIMENTO PELO SÉCULO XX}

A Educação Superior brasileira se revela efetivamente a partir do século XIX, através de cursos constituídos em vista do aparato necessário à vida da corte portuguesa - daí a sua característica e a sua orientação profissionalizantes -, num momento em que estava sendo instalada sob a direção de Wilhelm von Humboldt (1767-1835) a Universidade de Berlim desde os finais de 1808, uma expressão simbólica da universidade iluminista, concretamente emergente. Desde então, esteve presente, de forma latente e paulatina, no âmbito da cultura ocidental, um enfrentamento entre a formação acadêmica e a formação profissional, como se comentou anteriormente.

No Brasil, vários projetos de universidade se manifestaram durante os períodos colonial e imperial, entre o fim do século XVI e o XIX. Dentre eles, e como exemplo, ressalte-se o projeto de universidade apresentado em 06/08/1870, que estabelecia os seguintes fins para a educação superior, claramente orientado para a formação profissional e de caráter utilitarista: "[...] o exercício das mais nobres profissoes, o adiantamento do espírito humano e o progresso nacional considerado em diversas esferas da atividade social' (Apud SILVEIRA, 1984, p. 56).

Entretanto, a certidão de nascimento da universidade brasileira será lavrada com o Estatuto das Universidades Brasileiras, através do decreto $\mathrm{n}^{\circ} 19.851$ de 11 de abril de 1931, que estará dispondo que "o ensino superior no Brasil obedecerá, de preferência, ao sistema universitário, podendo ainda ser ministrado em institutos isolados [...]" (ESTATUTO DAS UNIVERSIDADES BRASILEIRAS, 1931, p. 51).

$\mathrm{O}$ artigo $1^{\circ}$ do referido Estatuto, inserido no Título I, Fins do Ensino Universitário, prescreve:

$O$ ensino universitário tem como finalidade: elevar o nível da cultura geral; estimular a investigação cientifica em quaisquer domínios dos conhecimentos humanos; habilitar ao exercício de atividades que requerem preparo técnico e científico superior; concorrer, enfim, pela educação do indivíduo e da coletividade, pela harmonia de objetivos entre professores e estudantes e pelo aproveitamento de todas as atividades universitárias, para a grandeza da Nação e para o aperfeiçoamento da Humanidade. (ESTATUTO DAS UNIVERSIDADES BRASILEIRAS, 1931, p. 51)

A Exposição de Motivos que acompanha o referido Estatuto, mas datada de 2 de abril de 1931, afirma a Universidade como uma unidade didática, porém:

[...] sua finalidade transcende ao exclusivo propósito do ensino, envolvendo preocupaçôes de pura ciência e de cultura desinteressada, [...] uma unidade social ativa e militante, isto é, um centro de contato, de colaboração e de cooperação de vontades e de aspiraçôes [...] que 
como unidade viva, tende a ampliar no meio social em que se organiza e existe, o seu círculo de ressonância e de influência, exercendo nela uma larga, poderosa e autorizada função educativa. [...] quanto à influência educativa que a Universidade deve exercer sobre o meio social, instituindo a extensão universitária, poderoso mecanismo de contato dos institutos de ensino superior com a sociedade, utilizando em beneficio desta as atividades universitárias. (EXPOSIÇÃO DE MOTIVOS DO MINISTRO FRANCISCO CAMPOS SOBRE A REFORMA DO ENSINO SUPERIOR, 1931, p. 22).

Alguns aspectos dessa citação sugerem associações com as idéias de Humboldt expostas anteriormente, quando afirma a universidade como lugar da 'pura ciência', que se estabelece pela 'colaboração' e pela 'cooperação'.

Em relação ao movimento universitário brasileiro, particularmente no tocante à pedagogia universitária, faz-se mister a seguinte reflexão: embora tenham ocorrido criações de universidade anteriormente, mas que não vingaram, a primeira universidade brasileira nasceu concretamente ao final da segunda década do século XX: a Universidade do Rio de Janeiro (a futura UFRJ), criada em 1920 pela União; e, ao final da terceira década, é criada, pelo Estado de Minas Gerais, a Universidade de Minas Gerais (a futura UFMG) em 1927. Estava por ser constituída a pedagogia universitária, para a qual professores e alunos são centrais.

Para Labouriau (1929), um líder na orientação do Inquérito de 1928, o qual veio a público pela obra $O$ Problema Universitário Brasileiro, o espírito universitário precisava ser criado: "É uma mentalidade a desenvolver. O primeiro passo, que se pode considerar preparatório, é prender mais estreitamente ao ensino os alunos e os professores. Depois, desenvolver o interesse público pelas questôes geraes" (p. 8).

Na visão de Raul Leitão da Cunha (1929), futuro Ministro da Educação nos anos 1940, o ensino superior brasileiro apresentava, então, deficiências muito importantes em vista da pedagogia universitária:

Quase todos nossos acadêmicos são visitantes efêmeros da Escola, principalmente porque nela não encontram atractivos interessantes, nem local apropriado para estudos e meditação. Assim, desobrigados da tarefa massadoira de assistir à aula, abandonam, apressados, o sitio em que deveriam permanecer as melhores horas do dia (1929, p. 30).

Tais expressōes concretas, presentes em depoimentos vindos a público em 1929 pela obra já mencionada, situam-se, na visão de Paim (1981), no decorrer do primeiro movimento de criação da universidade brasileira a partir da liderança da Associação Brasileira de Educação, criada em 1924, movimento este que tem seus desdobramentos e expressões, entre outros, na elaboração do Estatuto da Universidade Brasileira de 1931, bem como no Manifesto dos Pioneiros da Educação Nova de 1932. 
O segundo movimento brasileiro refere-se aos anos 1960, porém já ressoante nos anos 1950, o qual "[...] aspirava à democratização do ensino superior que mesmo depois de criada a Universidade, continuava elitista, segundo se dizia [...]" (PAIM, 1981, p. 9). Tratava-se de responder às novas demandas urbanas, industriais e tecnológicas. Na visão de Florestan Fernandes, essa década, marcada pela assunção do governo pelos militares, representa o triunfo da revolução burguesa no Brasil. As ressonâncias do Maio de 1968 também aqui se deram, das quais a Reforma Universitária de 1968 é um afluente. E, em resposta à democratização, realizaram-se a expansão e a interiorização da educação superior. Alguns dados revelam tal movimento: entre 1945 e 1960 o número de escolas de ensino superior cresceu 134,7\% em relação ao período entre 1930 e 1945.

Em complementação a tal interpretação de Antonio Paim (1981), pode-se dizer que, nos anos 1990, vem a público o terceiro movimento, em que se manifesta o significativo crescimento do setor privado, fazendo reverter, de maneira nítida, a hegemonia das universidades públicas do ponto de vista quantitativo. Observe-se que, apesar disso, o acesso à Educação Superior ainda se manifesta aquém de estatísticas compatíveis com as aspirações ao desenvolvimento científico e tecnológico. Ou seja, o elitismo da República Velha ainda bafeja os tempos da Nova República no âmbito da Educação Superior contemporânea. A seguinte observação delineia os limites desse terceiro movimento, na atualidade, além da necessidade de ponderar a respeito da propalada expansão:

A taxa de escolarização bruta dos cidadãos brasileiros que se encontram matriculados no ensino superior gira em torno de $15 \%$, proporção bem abaixo de outros paises da regiāo, como, por exemplo, Argentina (40\%), Uruguai (30\%), Chile (20,6\%), Venezuela (26\%) e Bolivia (20,6\%) (SOUSA, 2006, p. 145).

Por conseguinte, é problemático falar em pedagogia universitária, em sentido estrito, ao assumir as observações anteriores de Labouriau e de Raul Leitão da Cunha a respeito do problema universitário brasileiro, com base no Inquérito de 1928, seja em seu aspecto pedagógico, seja em relação ao ensino vinculado à pesquisa naquele momento em que as universidades do Rio de Janeiro e de Minas Gerais estavam em processo instituinte inicial, basicamente constituídas por uma aglutinação de cursos superiores.

Nessa direção, a pedagogia universitária, em sentido estrito, só pode ser pensada a partir da institucionalização do binômio indissociável entre o ensino e a pesquisa, através da Lei 5.540 de 28 de novembro de 1968, apesar da perspectiva aberta pelo Estatuto das Universidades Brasileiras de 1931, conforme comentários anteriores. A referida lei de 1968 expressa os norteamentos da reforma universitária de então: estabelece em seu artigo $1^{\circ}$ que "o ensino superior tem por objetivo a pesquisa, o desenvolvimento das ciências, letras e artes e a formação de profissionais de nivel universitário" (AGUIAR, 1997, p. 20); e o seu artigo $2^{\circ}$, que "o ensino superior indissociável da pesquisa, será ministrado em universidade, e, excepcionalmente, em estabelecidos isolados, organizados como instituiçôes de direito público ou privado" (AGUIAR, 1997, p. 20). 
Com relação à extensão, a referida Reforma Universitária a ela se refere nos artigos $17^{\circ}, 25^{\circ}$ e $40^{\circ}$, prevendo os cursos de extensão, como uma entre outras modalidades, tanto para as universidades como para os estabelecimentos isolados de ensino superior (artigos $17^{\circ}$ e $25^{\circ}$ ). Todavia, o artigo $40^{\circ}$ é explicito à extensão como uma atividade: " $A s$ instituiçôes de ensino superior: a) por meio de suas atividades de extensão, proporcionarão aos corpos discentes oportunidades de participação em programas de melhoria das condições de vida da comunidade e no processo geral de desenvolvimento" (AGUIAR, 1997, p. 29).

A Lei n ${ }^{\circ}$ 9.394, de 20/12/1996, que estabelece as atuais Diretrizes e Bases da Educação Nacional, em seu artigo $1^{\circ}$ firma a orientação de que "a educação abrange os processos formativos que se desenvolvem na vida familiar, na convivência humana, no trabalho, nas instituiçōes de ensino e pesquisa, nos movimentos sociais e organizaçôes da sociedade civil e nas manifestaçôes culturais" (grifos do autor).

$\mathrm{O}$ seu artigo $2^{\circ}$ fixa que as finalidades da educação nacional se estruturam em torno do "pleno desenvolvimento do educando, seu preparo para o exercício da cidadania e sua qualificação para o trabalho", especificando posteriormente, no artigo $21^{\circ}$, que a educação escolar abrange a educação básica - compreendida pela educação infantil e fundamental e pelo ensino médio - e a educação superior.

No corpo da referida LDB, esta é contemplada pelos artigos $43^{\circ}$ a $57^{\circ}$. Em relação à pesquisa, cabe atenção, em termos de princípios, às referências ao artigo $43^{\circ}$, o qual estabelece que a educação superior tem por objetivo o estímulo ao desenvolvimento do espírito científico (inciso I), o incentivo ao trabalho de pesquisa e investigação científica (inciso III).

Em relação à extensão, o mesmo artigo $43^{\circ}$, inciso VII, estabelece que cabe à educação superior "promover a extensão, aberta à participação, visando à difusão das conquistas e benefícios resultantes da criação cultural e da pesquisa científica e tecnológica geradas na instituição".

O Anteprojeto de Lei de Reforma da Educação Superior de 29/07/2005, embora esteja em discussão, apresenta também alguns princípios a serem levados em conta. $\mathrm{O}$ seu artigo $3^{\circ}$ propõe que a educação superior é "bem público que cumpre sua função social por meio das atividades de ensino, pesquisa e extensão". E que a mesma educação superior abrange o ensino em cursos de graduação, o ensino em programas de pós-graduação stricto sensu, a pesquisa e a produção intelectual, a extensão e a formação continuada.

Panoramicamente, portanto, a pedagogia universitária vem, desde as primeiras universidades estabelecidas nos anos 1920, manifestando-se como uma aspiração; entretanto, não se pode descurar das realizaçôes, como se houvesse um hiato entre os anos 1920 e a reforma de universitária de 1968. Entre a pedagogia universitária possível e a real, estão os esforços das universidades públicas e confessionais, grosso modo, dos anos 1920 aos anos 1960. A propósito, a observação de Maria de Lourdes A. Fávero é esclarecedora: 
Somente nos anos 1950, a implantação de tempo integral e dedicação exclusiva será efetivamente concretizada na Universidade do Brasil. Inicia-se nesse periodo um movimento para se desenvolver a pesquisa de forma institucionalizada em diferentes áreas do conhecimento, e como um trabalho a ser realizado em torno de alguns catedráticos. [...] no periodo de 1967-1968 passa a existir pesquisa institucional, com verbas. (2006, p. 94-95).

O ano de 1968, pelo menos legislativamente, demarca os norteamentos em torno da indissociabilidade entre o ensino e a pesquisa, uma delimitação que estabelecerá os rumos para as universidades brasileiras existentes, bem como para as universidades vindouras desde então. Certamente, a efetiva institucionalização da pós-graduação e da iniciação científica, além das agências de fomento à pesquisa, apresenta uma participação significativa nesse processo. Que se ressaltem as institucionalizações do CNPq e da Capes nos anos 1950. Desde então, uma nova face se estrutura para a configuração da pedagogia universitária. Além disso, e vinculado ao movimento contemporâneo, há que se refletir sobre a institucionalização dos centros universitários, presente nos decretos $\mathrm{n}^{\circ} 2.306$ de 19 de agosto de $1997, \mathrm{n}^{\circ} 3.860$, de 9 de julho de 2001 e $\mathrm{n}^{\circ} 5.773$, de 9 de maio de 2006.

Em conclusão: tais balizas - em torno dos três movimentos mencionados em relação à universidade brasileira - vêm em auxílio à avaliação do sentido da reforma da educação superior brasileira (trata-se do Anteprojeto de Lei de Reforma da Educação Superior de 29/07/2005), ainda em gestação, para captar as suas direçôes, bem como suas diferenças em relação ao projeto humboldtiano. Que ele aqui se apresente como um contraponto, sem pretender servir de inspiração reacionária. Afinal, desvelar o movimento contemporâneo implica conhecer como o passado deixa as suas marcas, muitas vezes de longa duração.

Que existam diferenças entre as instituiçōes de ensino superior é inegável, mas que as universidades ditas de ensino - o que implica um debate explicitado no início dos anos 1980, particularmente pelo Projeto Geres - vêm contribuindo para a pesquisa e para o desenvolvimento científico também é plenamente sustentável. Embora a distinção entre as universidades de ensino e de pesquisa esteja posta em discussão também contemporaneamente (SILVA FILHO, 2004), às vezes de uma forma dicotômica, é preciso afirmar que o ideário humboldtiano ainda está a inspirar reflexões sobre essa dicotomização, a qual acaba compartimentando o ensino e a pesquisa.

O projeto humboldtiano deixa implícita a defesa de uma universidade pública (ou seja, estatal), portanto sob os cuidados do Estado, mas isenta de suas interferências e/ou de seus interesses imediatos. Nesse nicho, habitam as discussões sobre a autonomia, sobretudo a financeira e administrativa. Entretanto, aí está afirmada a dimensão política da educação, que não pode perder de vista a sociedade a que ela serve. E viver essa tensão é inerente à universidade, ou seja: a renovação das interpretaçōes sobre ela se traduz comumente por crise. Entretanto, talvez fosse mais significativo qualificar-se como 
tensão, a não ser que se compreendam as crises como desafios que se renovam conjuntural e processualmente.

Metaforicamente, e em obediência a Ortega y Gasset, o qual assumiu ser o homem ele e as suas circunstâncias, pode-se compreender que a universidade e a educação superior expressam-se como tais associadas às suas circunstâncias. A universidade iluminista, a humboldtiana, guarda relaçóes intrínsecas com o liberalismo. Entretanto, a perspectiva que se delineia é a de que a universidade pública contemporânea, em nome do desenvolvimento científico e tecnológico, esteja isenta de tal horizonte; ou senão, que esteja sendo desbaratada pelo neoliberalismo. E talvez isso signifique mais do que um paradoxo.

Em relação à pedagogia universitária - associada às dimensões filosófico-política, ético-política, filosófico-educacional, histórica, legislativa, institucional e didáticopedagógica -, cabe indagar: tem ela seu alojamento somente em universidades, e não em outras instituições de ensino superior, tais como os centros universitários, quando contemporaneamente se estruturam em torno da pós-graduação, da pesquisa e da iniciação científica? Parece ser necessário compreender a pedagogia universitária em lato sensu, sob pena de cometer anacronismos em relação ao movimento da educação superior contemporânea.

\section{Referências}

AGUIAR, José Márcio (Comp.). Reformas do Ensino 1891 a 1996. Belo Horizonte: Lâncer, 1997, v. 2 .

ARAUJO, José Carlos S. O Progresso e a Educação: de sua genealogia às expressões no Triângulo Mineiro. In: SCHELBAUER, Analete Regina; ARAUJO, José Carlos S. (Orgs.). História da educação pela imprensa. Campinas: Alínea, 2007, p. 85-106.

ANTEPROJETO DE LEI DE REFORMA DA EDUCAÇÃO SUPERIOR DE 29/07/2005. Disponível em: <www.mec.gov.br>. Acesso em: 1.01.2008.

CABANAS, José Maria Quintana. Teoria de la educación: concepción antinômica de la educación. Edición reformada. Madri: Dykinson, 1995.

CUNHA, Raul Leitão da. A crise actual do ensino, no Brasil - seus factores e seus aspectos. In: $O$ problema universitário brasileiro: inquérito promovido pela Secção de Ensino Technico e Superior da Associação Brasileira de Educação. Rio de Janeiro: Encadernadora, 1929, p. 26-31.

DURKHEIM, Émile. A evolução pedagógica. Porto Alegre: Artes Médicas, 1995.

ESTATUTO DAS UNIVERSIDADES BRASILEIRAS. In: FÁVERO, Maria de Lourdes Albuquerque (Org.). Universidade do Brasil: guia dos dispositivos legais. Rio de Janeiro: EdUFRJ, 2000, v. 2, p. 51-83.

EXPOSIÇÃO DE MOTIVOS DO MINISTRO FRANCISCO CAMPOS SOBRE A REFORMA DO ENSINO SUPERIOR. In: FÁVERO, Maria de Lourdes Albuquerque (Org.). Universidade do Brasil: guia dos dispositivos legais. Rio de Janeiro: EdUFRJ, 2000, v. 2, p. 21-50. 
FÁVERO, Maria de Lourdes Albuquerque. UFRJ: origens, construção e desenvolvimento. In: MOROSINI, Marília (Org.). A universidade no Brasil: concepções e modelos. Brasília: Inep, 2006, p. $85-102$.

GINZO, Arsênio. Hegel y el problema de la educación. In: HEGEL, Georg Wilhelm Friedrich. Escritos pedagógicos. México: Fondo de Cultura Econômica, 1991, p. 7-69.

HUMBOLDT, Wilhelm von. Sobre a Organização Interna e Externa das Instituições Científicas Superiores em Berlim. Rio de Janeiro: Eduerj, 1997a, p. 79-100.

Escritos de filosofia de la historia. Madri: Editorial Tecnos, $1997 \mathrm{~b}$.

KANT, Immanuel. Resposta à pergunta: Que é "Esclarecimento” (“Aufklärung”). In: Textos seletos. Petrópolis: Vozes, 1974, p. 100-117.

. Sobre a pedagogia. Piracicaba, SP: Edunimep, 1996.

. O conflito das faculdades. Lisboa: Edições 70, 1993.

LABOURIAU, F. O problema universitário brasileiro. In: O problema universitário brasileiro: Inquérito promovido pela Secção de Ensino Technico e Superior da Associação Brasileira de Educação. Rio de Janeiro: Encadernadora, 1929, p. 7-13.

LIMA VAZ, Henrique Cláudio. Antropologia Filosofia I. São Paulo: Loyola, 1991.

LOURENÇO FILHO, Manuel Bergström. A educação, problema nacional. Revista Brasileira de Estudos Pedagógicos, Brasília, DF, v. 65, n. 150, p. 369-383, maio/ago. 1984.

PAIM, Antonio. Os novos caminhos da universidade. Fortaleza: Imprensa Universitária da UFC, 1981.

RIDDER-SYMOENS, Hilde (Ed.). Historia de la universidad en Europa. V. 1 - Las Universidades em la Edad Media. Bilbao: Universidad del Pais Vasco, 1994.

ROCHA, João Cezar de Castrop. Respostas à Pergunta: que é universidade? In: CASPER, Gerhard. Um mundo sem universidades? Rio de Janeiro: Eduerj, 1997, p. 15-34.

SILVA FILHO, Roberto Leal Lobo e. Universidades de pesquisa no Brasil. Folha de São Paulo, 20/09/2004, Tendências/Debates, p. A3.

SILVEIRA, Maria José. A evolução da concepção de universidade no Brasil. In: TUBINO, Manoel José Gomes (Org.). A universidade ontem e hoje. São Paulo, Ibrasa, 1984, p. 53-79.

SOUSA, José Vieira de. Restrição do público e estímulo à iniciativa privada: tendência histórica no Ensino Superior Brasileiro. In: SILVA, Maria Abadia da; SILVA, Ronalda Barreto (Orgs.). A idéia de universidade: rumos e desafios. Brasília: Líber Livro, 2006, p. 139-178.

VERÍSSIMO, José. A educação nacional. Porto Alegre: Mercado Aberto, 1985. 


\section{University pedagogy: educational-philosophical origin and Brazilian correlated aspects at the 20 th century \\ Abstract}

The aim is to configure a conceptualization of university pedagogy, primarily based on the thoughts of Humboldt (1767-1835), encountered in his work entitled "On the Internal and External Organization of Higher Education Scientific Institutions in Berlin", written in 1810, which reveals, basically, the plan about the university since the 19th century until nowadays. And, in second place, to discuss about the Brazilian university pedagogy, certainly related to the Humboldtian ideals, in three crucial moments of its constitution in the course of the 20th century: a) in the 1920s, by the university movement founded on the formation of the elite; b) in the years of 1950 and 60, by the movement relative to the democratization of Higher Education; and c) in the 1990s, with contemporary ressonances, by the movement entitled Higher Education "merchandising", when an admirable expansion of the private sector, but one that is certainly synchronized with the preceding movement.

Keywords: University pedagogy. Humboldt. Teaching. Research. Brazilian University. Higher Education.

\section{Pédagogie universitaire : genèse philosophique-éducationnelle et réalisations brésiliennes au XXe siècle}

\section{Résumé}

L'objectif est de configurer une conceptualisation de pédagogie universitaire, premièrement, sur base de la pensée de Humboldt (1767-1835), présente dans l'ouvre intitulée 'Sur l'Organisation Interne et Externe des Organisations Scientifiques Supérieures à Berlin', écrite en 1810, dans laquelle révèle, au fond, l'idéation autour de l'université depuis le siècle XIX jusqu’à nos jours. Et, en second lieu, l'objectif de verser sur la pédagogie universitaire brésilienne, certainement liée aux idéaux humboldtiens, en trois moments cruciaux de sa constitution au cours du siècle XX: a) dans les années 1920, par le mouvement universitaire fondé sur l'idée de la formation des élites; b) dans les années 1950 et 60, par le mouvement autour de la démocratisation de l'enseignement supérieur; et c) dans les années 1990, avec des résonances dans l'actualité, par le mouvement dénommé "marchandisage" de l'enseignement supérieur, quand il assiste à une admirable expansion du secteur privé, mais certainement en syntonie avec le mouvement précédent.

Mots clefs: Pédagogie universitaire. Humboldt. Enseignement. Recherche. Université brésilienne. Enseignement supérieur.

\section{Pedagogía universitaria: génesis filosófico educacional y realizaciones brasilenãs en el siglo $\mathbf{X X}$ \\ Resumen}

El objectivo es configurar una conceptualización de pedagogía universitaria, primeramente con base en el pensamiento de Humboldt (1767-1835), presente en la obra intitulada sobre la organización interna y externa de las instituciones cientificas superiores en Berlin, escrita en 1810, que revela, basicamente, el ideario acerca de la universidad desde el siglio XIX hasta nuestros dias. $Y$, en segundo lugar, el objectivo de versar sobre la pedagogía universitaria brasileña, ciertamente vinculada a los ideales humboldtianos, en tres momentos cruciales de su constitución durante el siglo XX: a) en años 1920, por el movimiento universitario fundado en la idea de formación de las elites; b) en los años 1950 y 60, por el movimiento en torno a la democratización de la educación superior; y c) en los años 1990, con ecos en la actualidad, por el movimiento denominado "mercantilización" de la educación superior, cuando se ve a una admirable expansión del setor privado, pero ciertamente en sintonía con el movimiento anterior.

Palabras-clave: Pedagogía universitaria. Humboldt. Enseñanza. Pesquisa. Universidad brasileña. Educación superior.

Recebido: $01.02 .2008 \cdot$ Aceito: 21.06 .2008 